\title{
Development of Action and the Clinical Continuum
}

\author{
Brian Hopkins \\ Department of Psychology, Lancaster University, Lancaster LA1 4YF, England
}

\begin{abstract}
The development of action is depicted as consisting of changes in the task-specific couplings between perception, movement, and posture. It is argued that this approach may provide a much needed basis from which attempts can be made at theoretically unifying the constituents of the clinical continuum (viz., early detection, diagnosis, prognosis, and intervention). Illustrative examples germane to this approach are given with regard to how posture serves as a constraint on the emergence of reaching movements and how cortical development influences the coordination of leg movements as revealed by a study involving infants with white matter lesions. Particular attention is paid to early detection and it is recommended that further improvements to this aspect of the clinical continuum can be derived from combining serial qualitative and quantitative (kinematic) assessments with brain-imaging techniques. It is emphasized that quantitati:e assessments should incorporate experimental manipulations of perception, movement or posture during transitional periods in development. Concluding comments include consideration of the timing of early intervention.
\end{abstract}

Reprint requests to: Brian Hopkins, Department of Psychology, Lancaster University, Lancaster LA1 4YF, England

\section{KEYWORDS}

corticospinal tracts; leg movements; motor equivalence; periventricular leukomalacia; ontogenetic adaptations; reaching movements

\section{A. INTRODUCTION}

More than 60 years ago, the German neurologist, von Weizsäcker (1940/1973), presented his Gestalt Circle Theory. The central tenet of his theory was that perception and action are inseparably linked at both the neural and behavioral levels of organization. Furthermore, the 'circle of causality' between perception and action could only be broken by pathological conditions that affected the functioning of the brain. Given that at the time, perception and movement control were studied in relative isolation from each other, these were indeed bold statements not shared by more empirically minded students of human behavior, with the possible exception of Bernstein (1967).

Turning to more recent times, von Weizsäcker's tentative claims have resurfaced in theoretical attempts to capture the mutual reciprocity between perception and action at both the level of behavior (for example, Gibson, 1975) and brain architecture (for example, Edelman, 1987). In addition, there is growing support for his claim that (cortical) brain pathology can result in the dissociation between (visual) perception and the goal-directed movements that constitute action (for example, see Milner \& Goodale, 1995). Such theorizing has also begun to make significant inroads into research on 
development, especially during the period of infancy (an excellent example of which can be found in the work of Adolph [1997] on the development of locomotion). What is lacking so far, however, in this approach to early development is to account for the changing relationship not only between perception and action but also between them and posture. In the context of early detection in particular, it is argued that changes in the functional relations between perception, movement, and posture in the development of action need to be accounted for if further improvements are to be made to this first stage of the clinical continuum.

In what follows, there is a brief overview of what comprises the clinical continuum and which raises the issue what is meant by 'normality'. Then, consideration will be given to the strengths and weaknesses of current methods of early detection, which are largely based on the qualitative or quantitative analyses of spontaneous or elicited movement patterns. Subsequently, the findings of two studies considered to be relevant to improving the potential of early detection are reviewed. One considers how the control of posture and movement cohere in the emergence of reaching and the other the link between (proprio-) perception and movement in the development spontaneous kicking. The latter two-part study also brings with it some insights into the development of the corticospinal tracts. Finally, concluding remarks include the suggestion that a perceptionaction approach as outlined here may provide the beginnings of a framework that can theoretically unify all aspects of the clinical continuum.

\section{B. THE CLINICAL CONTINUUM}

The provision of appropriate forms of therapeutic intervention for children with major or minor disabilities represents the end point of a series of interconnected clinical endeavors. These

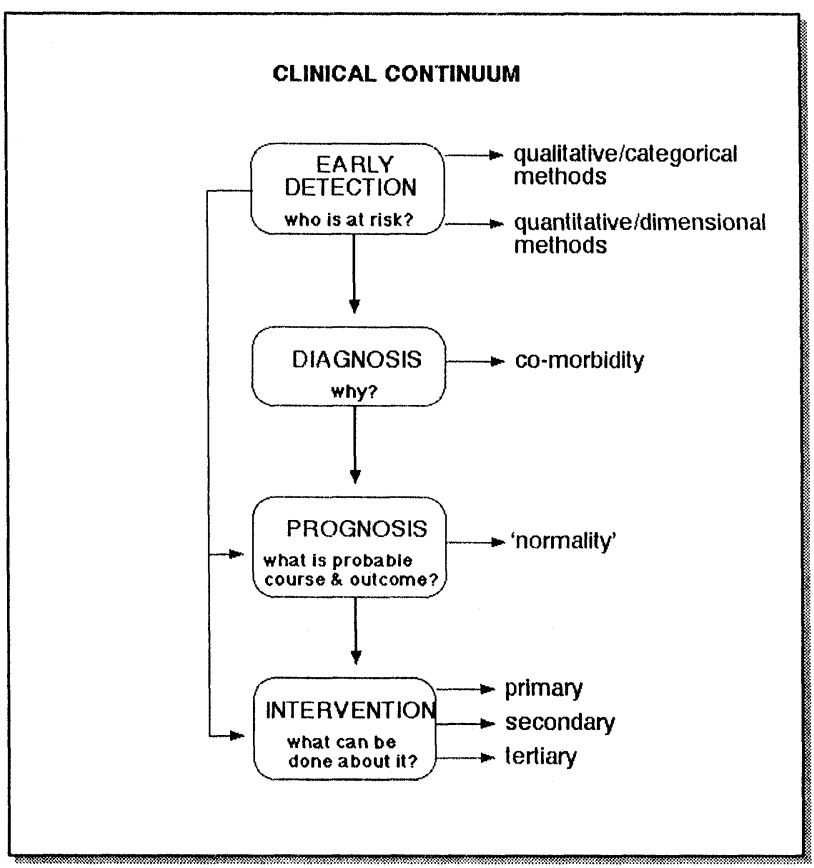

Fig. 1: The clinical continuum that contains a sequence of interrelated aspects, but with each one addressing a particular question. Topics relevant to each aspect that are discussed in the text are referred to on the right hand side of the figure. The continuum represents an ideal sequence of clinical activities starting with early detection and proceeding through diagnosis and prognosis to therapeutic intervention. Sometimes both prognosis and intervention may follow on from early detection (without diagnosis) as indicated by the thin arrowheaded lines. In these instances, primary intervention is the goal in an attempt to prevent the probable occurrence of some later emerging general disorder (for example, cerebral palsy or cognitive deficits in preterm infants).

other undertakings encompass early detection, diagnosis and prognosis and, together with intervention, form the clinical continuum (see Fig. 1).

Definitions of these four aspects of the clinical continuum as well as the main issues that confront each of them are given in Table 1. Where possible, reference is made to how they impinge upon research with clumsy children. 


\section{TABLE 1}

Definitions of the four aspects making up the clinical continuum, the main issues facing how each aspect is put into practice, and comments relevant to these problems

\begin{tabular}{|c|c|c|c|}
\hline Aspect & Definition & Issues involved & Comment \\
\hline $\begin{array}{l}\text { Early } \\
\text { detection }\end{array}$ & $\begin{array}{l}\text { Identification of those individuals at risk } \\
\text { for a functional disorder later in } \\
\text { development }\end{array}$ & $\begin{array}{l}\text { 1. How early in } \\
\text { development for } \\
\text { reliable identification? } \\
2 . \text { What is child at risk } \\
\text { for? }\end{array}$ & $\begin{array}{l}\text { Claim that a valid functionally based } \\
\text { instrument available for use in the } \\
\text { prenatal period (Prechtl, 1999) }\end{array}$ \\
\hline Diagnosis & $\begin{array}{l}\text { 1. Assignment of an individual or } \\
\text { disorder to class within taxonomy(e.g. } \\
\text { DSM-IV; ICD 10) } \\
\text { 2. Determining cause(s) of disorder (why } \\
\text { a person is likely to have it) } \\
\text { 3. Three types } \\
\text { a. Clinical diagnosis based on signs and } \\
\text { symptoms } \\
\text { b. diagnosis by exclusion: ruling out all } \\
\text { but one disease thought to be } \\
\text { determinant } \\
\text { c. differential diagnosis: identifying } \\
\text { which of two or more diseases with } \\
\text { similar signs or symptoms is } \\
\text { determinant }\end{array}$ & $\begin{array}{l}\text { 1. Comorbidity problem: } \\
\text { many disorders are not } \\
\text { discrete categories. } \\
\text { Thus: } \\
\text { 2. Difficult to distinguish } \\
\text { between primary and } \\
\text { secondary disorder } \\
\text { 3. In such instances, a. } \\
\text { and b. types of } \\
\text { diagnosis are not } \\
\text { applicable }\end{array}$ & $\begin{array}{l}\text { 1. Classifying child as clumsy relies } \\
\text { on diagnosing signs (standardized } \\
\text { test performance) and symptoms } \\
\text { (from subjective judgments made } \\
\text { by parents and/or teachers using a } \\
\text { questionnaire) } \\
\text { 2. Diagnosis of cerebral palsy } \\
\text { complicated because } 17 \% \text { to } 60 \% \\
\text { of such cases have no evident } \\
\text { perinatal or neonatal etiology } \\
\text { (Stanley et a., 2000) }\end{array}$ \\
\hline Prognosis & $\begin{array}{l}\text { Making predictions about the probable } \\
\text { developmental course and outcome of } \\
\text { individual diagnosed with particular } \\
\text { disorder }\end{array}$ & $\begin{array}{l}\text { 1. For clumsy children: } \\
\text { do they 'grow out of it' } \\
\text { or does it continue up } \\
\text { to and beyond } \\
\text { adolescence? } \\
\text { 2. Comorbidity problem: } \\
\text { which disorder most } \\
\text { dictates course and } \\
\text { outcome? }\end{array}$ & $\begin{array}{l}\text { Suggestion that isolated GM/IVH } \\
\text { may predict less severe disorders } \\
\text { such DCD (Paneth, Pinto-Martin, } \\
\text { 1991) }\end{array}$ \\
\hline Intervention & $\begin{array}{l}\text { 1. Treatment designed to prevent, } \\
\text { ameliorate, or overcome signs and } \\
\text { symptoms associated with disorder } \\
\text { 2. Three types: } \\
\text { a. primary intervention: reducing } \\
\text { incidence of disorder before it occurs } \\
\text { b. secondary intervention: treating } \\
\text { disorder while it is becoming } \\
\text { established } \\
\text { c. tertiary intervention: treating } \\
\text { disorder after it is established }\end{array}$ & $\begin{array}{l}\text { 1. Does intervention } \\
\text { result in predicted } \\
\text { effect? } \\
\text { 2. For how long are the } \\
\text { effects sustained after } \\
\text { intervention stops? } \\
\text { 3. Does intervention } \\
\text { avoid any iatrogenic } \\
\text { effects? }\end{array}$ & $\begin{array}{l}\text { 1. Tertiary intervention studies with } \\
\text { clumsy children have been } \\
\text { infrequent } \\
\text { 2. Such studies have not produced } \\
\text { consistent findings with regard to } \\
\text { the efficacy of partlicular approach } \\
\text { (Miyahara, 1996)) }\end{array}$ \\
\hline
\end{tabular}

DCD: Developmental Coordination Disorder; GM/IVH: germinal matrix/intraventricular haemorrhage 
There are three common denominators with regard to each of these aspects of the clinical continuum. To begin with, they all require the integration of a variety of sources of information (for example, biochemical assays, brain scans, physiological measures, assessments of elicited responses, and evaluations of spontaneous movements). The relative clinical significance assigned to the various sources remains a problem. Another commonly shared issue is what constitutes 'normality'. According to Feinstein (1977), the term normality can have two general meanings: isolated and correlated normality. Isolated normality is the same as 'normality as average' and as such depends on normative age standards derived from standardized (developmental) tests. Correlated normality involves relating scores on a broadly-based test (for example, the Movement $\mathrm{ABC})$ to some other variable that measures a specific function (for example, reading ability). It appears that research on clumsiness is becoming increasingly reliant on this latter approach as a means of identifying subtypes of children initially classified as DCD according to the strictures of some predefined notion of isolated normality. A final consideration that permeates the clinical continuum concerns its starting point: an instrument of early detection should ensure that the rates of false positives and false negatives are as low as possible, with perhaps the latter being the crucial benchmark as to its discriminative validity. If not, then diagnosis and possibly subsequent steps along the clinical continuum could be jeopardized.

Returning to Fig. 1, notice that early detection has been depicted as resting on two distinct methods of evaluation: one derived from qualitative (or categorical) assessments and the other from quantitative (or dimensional) assessments. In terms of research on childhood clumsiness, quantitative data is delivered, for example, by the Movement $\mathrm{ABC}$, whereas Touwen's (1979) neurological examination represents a qualitative form of assessment. What are the respective roles of these two methods, particularly in the context of early detection?

\section{QUALITATIVE VERSUS QUANTITATIVE METHODS}

The qualitative assessments of, for example, the spontaneous general movements of young infants is epitomized in the ground-breaking work of Hadders-Algra and her co-workers (for example, see Hadders-Algra et al., 1997), as well as that of Prechtl and colleagues (for example, see Prechtl et al., 1997). Based on judgments about the quality with which such movements are expressed, this method of direct observation is not overly timeconsuming, simple to use and more readily matches clinical practice with its propensity for regarding disorders as qualitatively distinct entities relative to quantitative assessments. For its proper application, however, qualitative assessment requires extensive clinical experience and clear standards of what composes the normal range of age-specific behavior. Without such requirements "...qualitative assessments run the danger of producing arbitrary and artifactual boundaries in separating 'normal' form 'abnormal' and the creation of catch-call categories to cover any uncertainties between these two extreme judgements" (Hopkins, 2002, p. 307).

For their part, quantitative assessments (for example, stemming from kinematic analyses of limb movements) can help to address these problems. At the same time, such assessments can enable the underlying pathology in control mechanisms to be specified more precisely (see Sec. F). This benefit, when allied with a qualitative method of assessment, can be found in research on the gait patterns of children with cerebral palsy (Gage, 1991). Thus, in general, 
early detection, as well as diagnosis, prognosis, and treatment evaluation, will be improved through the blending of repeated qualitative and quantitative assessments. In conjunction with serial brain imaging, they serve as complementary sources of information, each with their own strengths and weaknesses, from which clinical decisions can be made. Such decisions should also profit from taking account of the age-specific dependencies between perception, movement, and posture. This suggestion is particularly apposite for the practice of early detection.

\section{EARLY DETECTION: TAKING ACCOUNT OF PERCEPTION, MOVEMENT, AND POSTURE}

The departure point for this topic is the cerebellum of the electrical fish Gnathonemus petersii (Bell \& Szabo, 1986). Despite the great size of its cerebellum, giving it a brain/weight ratio greater than a human adult, this moromyriad does not possess outstanding motor abilities. What it does have is a highly refined sensory system in which the cerebellum, together with midbrain homologues of the colliculli, plays a crucial role in detecting sense information from electroreceptors. Thus, the cerebellum in this fish is a sensory rather than just a motor organ as with echolocating bats and cetaceans who also have hypertrophied cerebella.

The point of mentioning this intriguing fish is that labeling brain systems as either motor or sensory may prove to be a fallacious exercise because they can be both. More generally, and at another level, (Gibson, 1975) posited something similar when referring to the inseparability of perception and action. In his view, there is a circular causality between them such that actions constrain or enhance what is perceived and what is perceived constrains or guides actions. Actions themselves, however, are composed of task- specific movements. Consequently, development consists of changes in perception (for example, binocular vision that becomes adult-like at about 4 months) leading to changes in movements subserving a particular action relative to a specific task (for example, reaching for and grasping a suspended object) and vice versa (for example, the ability to crawl creates new forms of perceptual experience).

What is lacking in this scenario is reference to a mutual dependency existing between movement and posture. This dependency can be depicted as follows: posture imposes constraints on the sorts of movements that are possible while movements constrain the organization of posture (see Fig. 2).

Extending the scenario in this way portrays the development of action as resulting from changes in the task-specific couplings between perception, movement, and posture such that a change in one component will give rise to changes in the other two. For example, a transformation from a bodycentered to a spatially-oriented posture typically

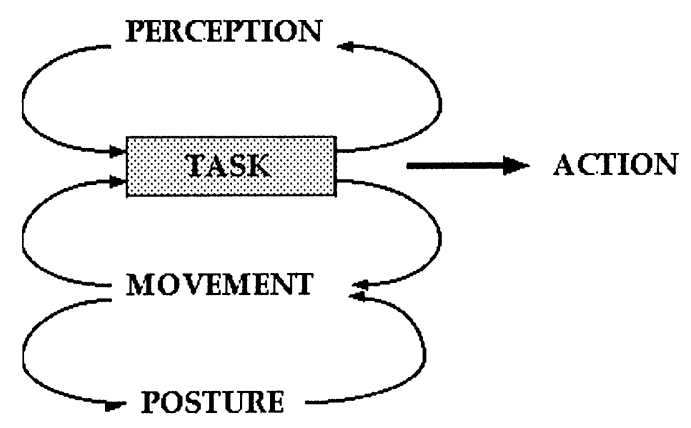

Fig. 2: Perception, movement and posture depicted as the components of the perception-action approach to development. According to this approach, developmental transformations in action are the result of changes in the taskspecific couplings between the components. 
occurring at around 3 months of age (Geerdink et al., 1994) will propagate change in the sorts of movements that are possible. In turn, these new movements will alter what the infant is capable of perceiving. Furthermore, change might also be induced by alterations in the nature of the task.

Task-induced changes in the movements of young infants is well exemplified in the work of van der Fits and colleagues (1990a; 1990b). In one study (1999a), they showed that healthy fullterm (FT) infants even as young as 3 months could adjust their postural muscles during goal-directed movements to account for variations in position in space (viz. supine, sitting semi-reclined, sitting upright). In another study, they found that relatively healthy preterm (PT) infants followed up from 4 to 8 months of corrected age were unable to make such task-specific adjustments due to a high amount of postural activity across all three positions in space (1999b). This difference between FT and PT infants is open to interpretation with recourse to the notion of motor equivalence (namely, a variety of different muscle contractions and joint rotations can be recruited to produce the same outcome). Thus, what typifies normal development is the ability to modify posture so that actions are appropriate to the demands of a particular task. In contrast, infants at risk for one or other developmental disorder such as DCD may lack this ability arising from an inadequate sensitivity to external perturbations that accompany positional changes in space. Consequently, facilitating postural control can enhance the performance of goal-directed movements in such infants-a topic that is addressed in the next section by means of an example from a recent study.

\section{E. EXAMPLE 1: POSTURE AND REACHING}

In this study, 6-month-old infants who could not sit alone performed reaching movements when seated upright in a modified chair and confronted with a small object in the body midline (Hopkins \& Rönnqvist, 2002). The modifications provided support for the long muscles of the back, the hips and upper legs as well as inducing extension of the spinal column (see Fig. 3).

High-speed, 3D video recordings were made of their arm and head movements when seated in the modified chair. The resultant kinematics were compared with those obtained with the infant sitting in an unmodified chair. Among other things, it was found that reaching was smoother (contained fewer movement units) when the infants were in the modified chair, but more so for the right than left arm (see Fig. 4). In addition, the head was more stable during reaching in this condition.

This study has potential implications for both early detection and intervention. For example, subjecting PT infants to seating modifications that provide additional postural support may help to distinguish those really at risk for disordered development from those who are less likely to manifest subsequent impairments or disabilities

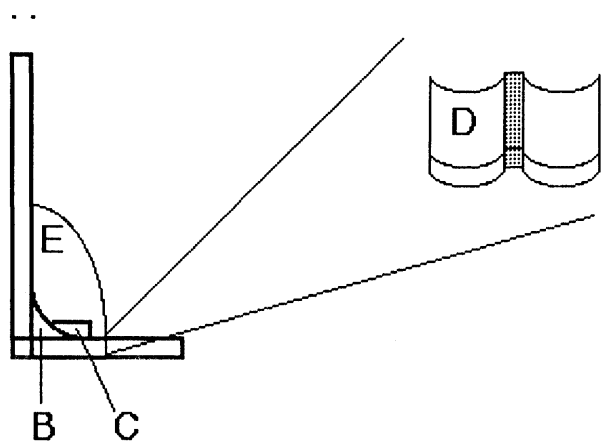

Fig. 3: Modifications made to a commercially produced infant chair: back rest 90 degrees to the sitting surface (A), a sacral pad (B), a raised ledge on which the infant sits $(C)$, wells into which the upper legs are inserted (D), and wedges placed against the hips (E). 
(namely, compromised infants may show an inability to adjust their posture to such modifications and thus any beneficial effects for their actions). In terms of (tertiary) intervention, seating designs for promoting postural control and movements of the upper extremities in children diagnosed as being cerebral palsied have a long history of use in the practice of physical therapy (see Mulcahy \& Poutney, 1986; Reid, 1996). So far, the benefits of these designs for such children amount to only promising claims, perhaps because of a lack of evaluations using appropriate controls and more objective measures.

At least, the kinematic parameters that were incorporated into the present study might contribute to improving the scientific rigor with which these evaluations are conducted. In the next section, we

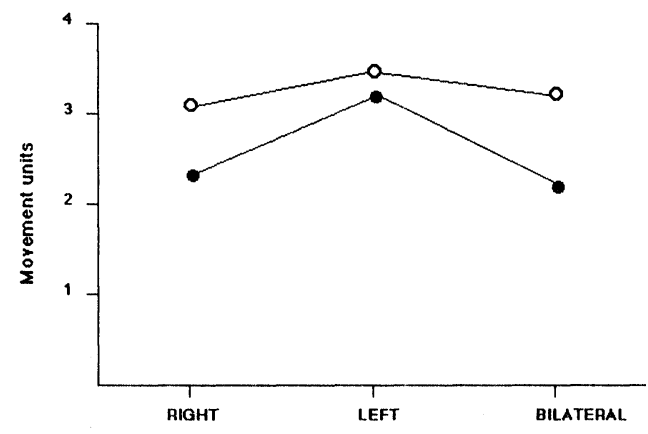

Fig. 4: Mean number of movement units (MUs) contained in unilateral (right or left arm) and bilateral reaches made when infants seated in unmodified (o) and modified ( $\bullet$ ) chair. Overall, there were significantly fewer MUs for reaches in the modified chair $[F(1,207)=11.30, p<.001]$. More specifically, there were significantly less MUs during unilateral right and bilateral reaching movements compared to unilateral left arm reaches in this condition. shift from quantitative assessments of reaching to their use in kinematic registrations of spontaneous leg movements performed by healthy infants and those with a verified brain lesion. What differences in performance do they detect between the two groups of infants?

\section{F. EXAMPLE 2: PERIVENTRICULAR LEUKO- MALACIA AND KICKING MOVEMENTS}

Periventricular leukomalacia (PVL) consists of bilateral necrosis in the periventricular white matter, which leads to the formation of cystic lesions at the corners of the lateral ventricles in the frontal, in the parietal, and less often, in the occipital regions. Present in about $9.2 \%$ of very preterm (VPT) infants but varying according to gestational age (Zupan et al., 1996), the causes of PVL are a matter of debate. Nevertheless, one long-term outcome is indisputable: in most VPT infants, PVL is associated with spastic diplegia (Volpe, 1995). Less severe forms of PVL have been implicated in the etiology of clumsiness (Hadders-Algra, in press) and related conditions like the Nonverbal Learning Disabilities Syndrome (Rourke, 1995).

In a study of PT infants with PVL verified by MRI, 3-D movement registrations were made of their spontaneous kicking movements in supine and compared with those of healthy FT infants at the (corrected) ages of $6,12,18$, and 26 weeks (Vaal et al., 2000). For those PT infants with the severest forms of PVL, the cross-correlations between the three joints of the (right) leg during kicking became increasingly higher over age compared with their healthy counterparts who had marked decreases in values after 12 weeks (see Fig. 5 for hip-knee cross-correlations).

Each infant with severe PVL had extensive damage to the corticospinal tracts, which suggests that they are involved in the regulation of intralimb 


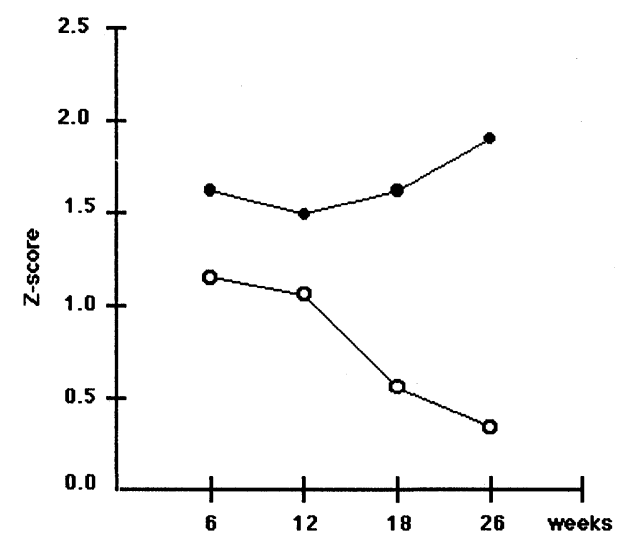

Fig. 5: Mean hip-knee correlations, converted to Z-scores, obtained longitudinally for healthy fullterm infants (o) and those with periventricular leukomalacia $(\bullet)$ during spontaneous kicking at the (corrected) ages of 6, 12, 18 and 26 weeks. Excluded from this figure are those infants with mildly and moderately abnormal indications of periventricular leukomalacia. Similar age-related trends were found for the hip-ankle and knee-ankle cross-correlations (see Vaal et al., 2000).

joint dissociations between 4 to 6 months of age. These tracts do not appear to play a direct role in interlimb coordination as there were no group differences across age in the relative frequency of simultaneous and alternating kicking movements.

To investigate the possibility that the coordination between leg movements is not regulated directly by the corticospinal tracts, a subsequent study was carried out (Vaal et al., 2002). Now, small weights were applied to the right leg of PT infants with PVL and their healthy FT counter-parts at 26 weeks corrected age (the age at which infants with and without PVL differed most in terms of intralimb coordination as revealed in the previous study).
In short, there were no differences in the relative frequency of alternating and simultaneous kicking between the two groups of infants -an outcome lending further support to the contention that cortical centers are not involved in the regulation of interlimb coordination. The PVL infants, however, increased their overall rate of kicking in the weighted condition relative to baseline (without weighting), which was not the case for the FT group.

The latter finding not only implicates the corticospinal system in adjusting the combined kicking frequency of both legs to an external perturbation but also says something about the coupling between proprioception and movement in healthy and in brain-damaged infants. One possibility is that the former galvanized functional synergies in such a way that they did not have to increase kicking frequency when the leg was weighted. In contrast, the PVL infants 'overreacted' to weighting the leg as shown by increases in the frequency of kicking compared to baseline. This difference implies perhaps that the healthy developing nervous system can increasingly exert a feedforward control over proprioception, whereas one compromised by cortical damage reacts in a feedback mode, at least with regard to leg movements. The ability to use a feedforward mode of control, perhaps by means of adjusting muscle torques to produce similar amounts of kicking in the weighted and baseline conditions, is probably achieved sooner than 6 months after birth (see Schneider et al., 1990). Representing another example of motor equivalence, this and other findings in the study also stress quantitative (kinematic) assessments as a useful adjunct to methods of early detection.

Returning to the point that the corticospinal tracts do not seem to play a major role in interlimb coordination, an alternative possibility in this respect could be the mesencephalic locomotor region (MLR). Electrical stimulation of this 
circumscribed region of the brain stem induces a normal pattern of walking in decerebrate cats on a treadmill (Shik \& Orlovsky, 1976). Similar findings have been reported for the neonatal rat (Atsuta et al., 1990), which suggests that this monoarminergic supraspinal descending pathway involved in the control of spinal rhythm generators is functional at birth. In infants with cortical PVL, the MLR is most probably not damaged, thus enabling them to coordinate movements of the legs in ways that are indistinguishable from healthy controls. This suggestion, however, has two caveats. First, other brain stem structures like the subthalamic locomotor region and the pontine locomotor region (viz., the pendunculopontine nucleus) can generate walking movements when stimulated (Armstrong, 1988). At present, how they and the MLR interact in the control of normal locomotion is unknown. Second, and most important, it still has to be demonstrated that these locomotor regions have homologs in the human.

\section{G. CONCLUDING REMARKS: BACK TO THE CLINICAL CONTINUUM}

The main argument in this paper has been that a greater understanding of the links between perception, movement, and posture in the development of action can engender further improvements in the instruments of early detection, as well as in other aspects of the clinical continuum. As part of this theoretically-driven venture, attempts should be made to test the functional integrity of the young nervous system through 'tweaking' it with the appropriate experimental manipulations (for example, by means of variations in spatial position, load, and other mechanical perturbations). But when should such 'tweaking' take place? One suggestion rests on the assumption that the susceptibility to task-induced changes in action could be particularly marked during transitional periods in development when there is a heightened sensitivity to external perturbations (see Hopkins et al., 1993). During these periods, which can be empirically verified (see Hopkins, 2001), infants whose nervous systems have been adversely affected in some way may display an inability to achieve motor equivalence across variations in experimental conditions. In other words, they evince a lack of functional plasticity. Such children might, of course, take longer to achieve a particular transition or even not make it all.

Moving to the other end of the clinical continuum, timing should also be a consideration as to when primary or secondary intervention is most appropriate. More to the point, the question is how early it should be applied? One answer (Hopkins, 2002) stems from the concept of ontogenetic adaptations (Oppenheim, 1981): certain structures and functions are needed for survival during one period of development, but they may be unnecessary (or even detrimental) for adaptations at later ages. Consequently, these structures and functions must be eliminated, suppressed, or reorganized in the course of normal development. At the functional level, such a major change in human development resulting in better adaptation to the extrauterine environment is evident some 2 to 3 months after birth (Prechtl, 1984). Thus, therapeutic intervention before about 3 months could create iatrogenic effects, due to it sustaining prenatal adaptations that would otherwise disappear about this age in normal development. This view does not run counter to current medical practice with regard to preterm infants, some of which is directed towards catering for their poor active postural control. Rather, this notion warns against the penchant for 'intervention as early as possible' that is typical of some advocates for programs of sensory stimulation with such infants.

As a final point, a testable theory embracing all aspects of the clinical continuum is lacking. 
Without new theoretical impulses, the practice of early detection and the rest will only stagnate. One suggested impulse derives from Edelman's (1987) Neuronal Group Selection Theory (Hadders-Algra, 2000). This theoretical perspective is in many ways consonant with the perception-action approach to development, all too briefly outlined in the present paper. Together, they could provide an impetus for us to integrate each aspect of the clinical continuum into an all encompassing theory that is applicable to research on developmental disorders. Such would be particularly beneficial for future studies on children who are afflicted with clumsy behavior, given that in the past there has been a paucity of theorizing about how the triad of perception, movement, and posture codevelop in such children.

\section{REFERENCES}

Adolph KE. 1997. Learning in the development of infant locomotion. Monographs of the Society for Research in Child Development, Serial No. 251, Vol. 62, No. 3.

Armstrong DM. 1988. The supraspinal control of mammalian locomotion. J Physiol 405: 1-37.

Atsuta Y, Garcia-Rill E, Skinner B. 1990. Characteristics of electrically induced locomotion in rat in vitro brain stem-spinal cord preparation. J Neurophysiol 64: 727-735.

Bell CC, Szabo T. (1986). Electroreception in monymyriad fish: central anatomy. In: Bullock TH, Heiligenberg W, eds, Electroreception. New York, NY, USA: Wiley; 375-422.

Bernstein NA. 1967 The Coordination and Regulation of Movement. Oxford, UK: Pergamon; 196.

Edelman GM. 1987. Neural Darwinism: The Theory of Neuronal Group Selection. New York, NY, USA: Basic Books; 371.

Feinstein AR. 1977. Clinical Biostatistics. St. Louis, Missouri, USA: Mosby; 468.

Gage JR. 1991. Gait Analysis in Cerebral Palsy. London, UK: Mac Keith Press; 206.

Geerdink JJ, Hopkins B, Hoeksma JB. 1994. The development of head position preference in preterm infants beyond term age. Dev Psychobiol 27:
153-168.

Gibson JJ. 1979. The Ecological Approach to Visual Perception. Boston: Houghton-Mifflin; 332.

Hadders-Algra M. 2000. The neuronal group selection theory: promising principles for understanding and treating developmental motor disorders. Dev Med Child Neurol 42: 707-715.

Hadders-Algra M. In press. The clumsy child - at the border of cerebral palsy? In: Velcikovic Perat M, Neville B, eds, Cerebral Palsy. Amsterdam, The Netherlands: Elsevier Science.

Hadders-Algra M, Klip-van den Nieuwendijk AWJ, Martijn A, van Eykern, LA. 1997. Assessment of general movements: towards a better understanding of a sensitive method to evaluate brain function in young infants. Dev Med Child Neurol 39: 88-98.

Hopkins B. 2001. Understanding motor development: insights from dynamical systems perspectives. In: Kalverboer AF, Gramsbergen A, eds, Handbook on Brain and Behavior in Human Development. Dordrecht: Kluwer; 591-620.

Hopkins B. 2002. Developmental disorders: an actionbased account. In: Connolly KJ, Valsiner J, eds, Handbook of Developmental Psychology. London, UK: Sage; 292-329.

Hopkins B, Beek PJ, Kalverboer AF. 1993. Theoretical issues in the longitudinal study of motor development. In: Kalverboer AF, Hopkins B, Geuze R, eds, Motor Development in Early and Later Childhood: Longitudinal Approaches. Cambridge, UK: Cambridge University Press; 343-371.

Hopkins B, Rönnqvist L. 2002. Facilitating postural control: effects on the reaching behavior of 6 month-old infants. Dev Psychobiol 40: 168-182.

Milner AD, Goodale MA. 1995. The Visual Brain in Action. Oxford, UK: Oxford University Press; 248.

Miyahara M. 1996. A meta-analysis of intervention studies on children with developmental coordination disorder. Corpus, Psyche et Societas 3: 11-18.

Mulcahy MC, Poutney TE. 1986. The sacral paddescription of its clinical use in seating. Physiotherapy 72: 473-474.

Oppenheim RW. 1981. Ontogenetic adaptations and retrogressive processes in the development of the nervous system and behavior: a neuroembryological perspective. In: Connolly KJ, Prechtl HFR, eds, Maturation and Development: Biological and Psychological Perspectives. London, UK: Heinemann; 73-109. 
Paneth N, Pinto-Martin J. 1991. The epidemiology of germinal matrix/intraventricular hemorrhage in preterm infants and hypoxic-ischemic encephalopathy in full-term infants. In: Kiely $M$, ed, Reproductive and Perinatal Epidemiology. Boca Raton, Florida, USA: CRC Press; 371-399.

Prechtl HFR, ed. 1984. Continuity of Neural Functions from Pre- to Postnatal Life. Oxford, UK: Blackwell; 255.

Prechtl HFR. 1999. How can we assess the integrity of the fetal nervous system? In: Arbeille P, Manlik D, Laurini RN, eds, Fetal Hypoxia. New York, NY, USA: Parthenon; 109-115.

Prechtl HFR, Einspieler C, Cioni G, Bos AF, Ferrari F, Southeimer D. 1997. An early marker of developing neurological deficits after perinatal brain lesions. Lancet 349: 1361-1363.

Reid D. 1996. The effects of the saddle seat on seated control and upper-extremity movement in children with cerebral palsy. Dev Med Neurol 38: 805-815.

Rourke BP, ed. 1995. Syndrome of Nonverbal Learning Disabilities: Neurodevelopmental Manifestations. New York, NY, USA: Guilford Press; 253.

Schneider K, Zernicke RF, Ulrich BD, Jensen JL. 1990. Understanding movement control in infants through the analysis of limb intersegmental dynamics. J Motor Beh 22: 493-520.

Shik ML, Orlovsky GN. 1976. Neurophysiology of locomotor automatism. Physiol Rev 56: 465-501.

Stanley F, Blair E, Alberman E. 2000. Cerebral Palsies: Epidemiology and Causal Pathways. London, UK:
Mac Keith Press; 251.

Touwen BCL. 1979. Examination of the Child with Minor Neurological Dysfunction. London, UK: Heinemann.

Vaal J, van Soest AJ, Hopkins B, Sie LTL. 2002. Spontaneous leg movements in infants with and without periventricular leukomalacia: effects of unilateral weighting. Behav Brain Res 129: 8392.

Vaal J, van Soest AJ, Hopkins B, Sie LTL, van der Knaap MS. 2000. Development of spontaneous leg movements in infants with and without periventricular leukomalacia. Exp Brain Res 135: 94-105.

van der Fits IBM, Klip AWJ, van Eykern LA, Hadders-Algra M. 1999a. Postural adjustments during spontaneous and goal-directed arm movements in the first half of year of life. Behav Brain Res 106: 75-90.

van der Fits I BM, Flikweert ER, Stremmelaar EF, Martijn A, Hadders-Algra M. 1999b. Development of postural adjustments during reaching in preterm infants. Pediatr Res 46: 1-7.

Volpe JJ. 1995. Neurology of the Newborn. $3^{\text {rd }}$ ed. Philadelphia, Pensylvania, USA: Saunders; 876.

von Weizsäcker VF. 1940/1973. Die Gestaltkreislehre. Theorie der Einheit von Wahrnehmung und Bewegung. Frankfurt, Germany: Suhrkamp; 179.

Zupan V, Gonzalez P, Tacaze-Masmonteil T, Boithas C, d'Allest A-M, Dehan M, Gabilan J-C. 1996. Periventricular leukomalacia: risk factors revisited. Dev Med Child Neurol 38: 1061-1067. 

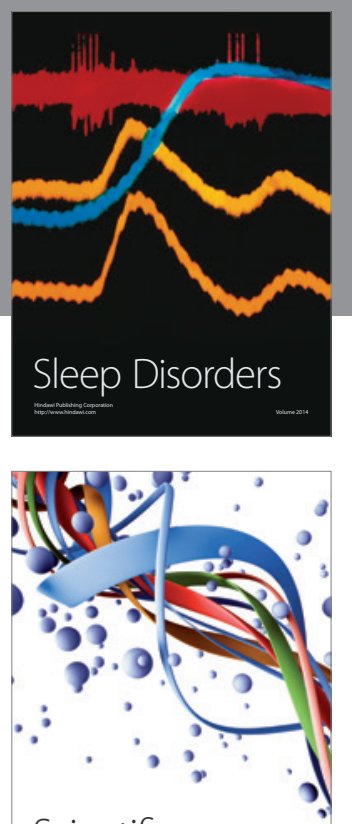

Scientifica
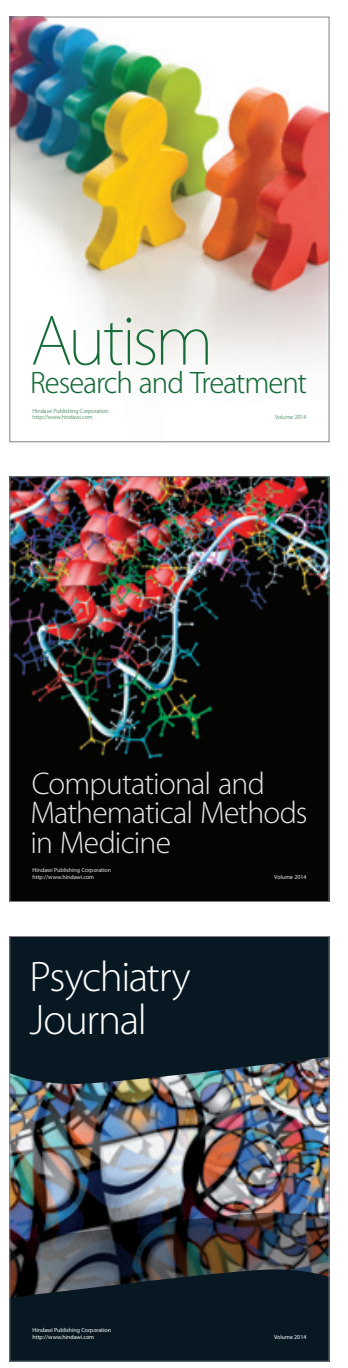
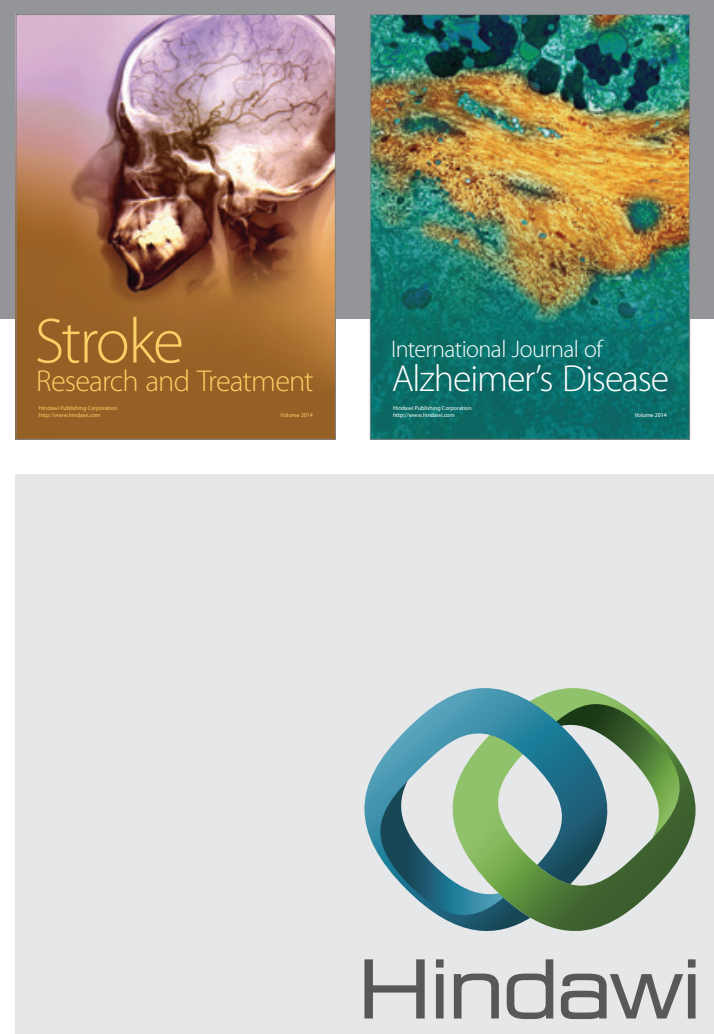

Submit your manuscripts at

http://www.hindawi.com
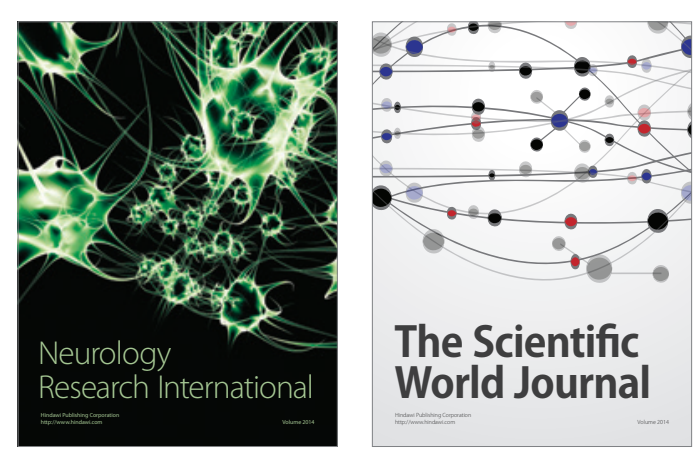

The Scientific World Journal

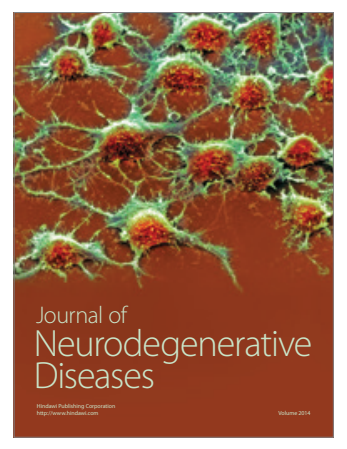

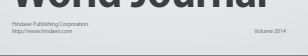

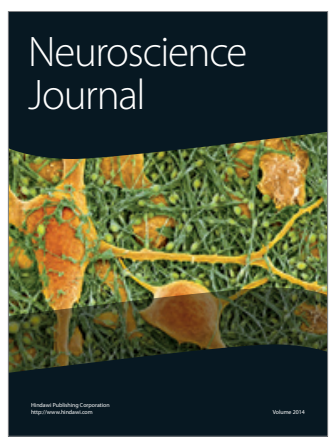

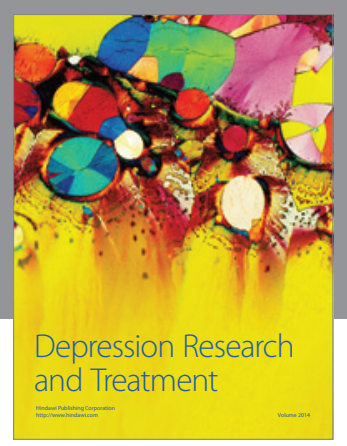
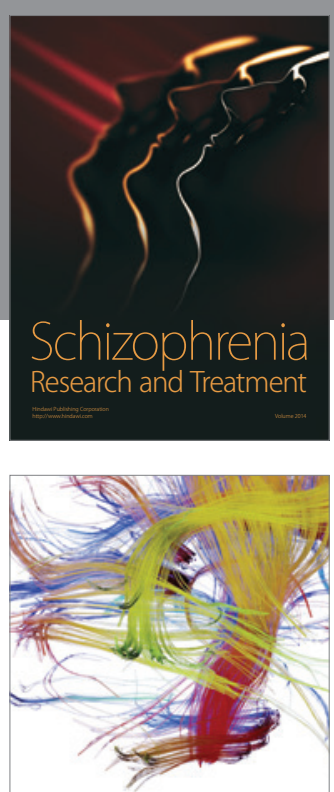

Brain Science

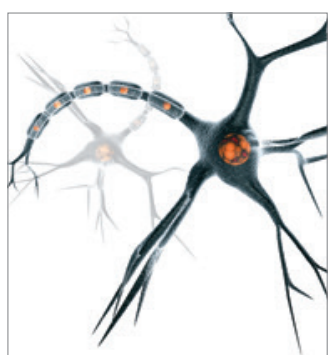

Neural Plasticity
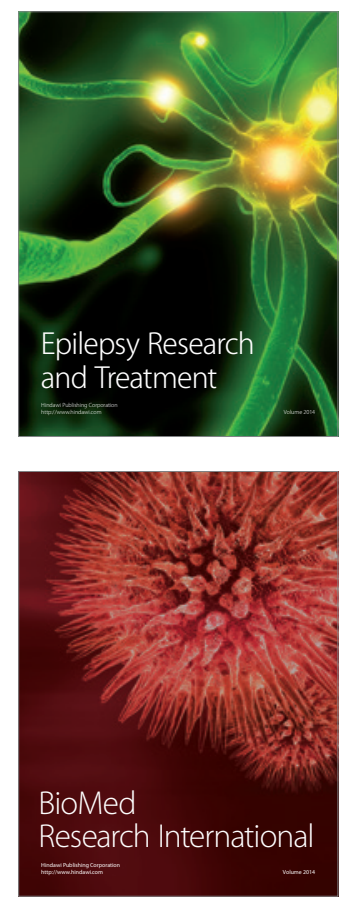

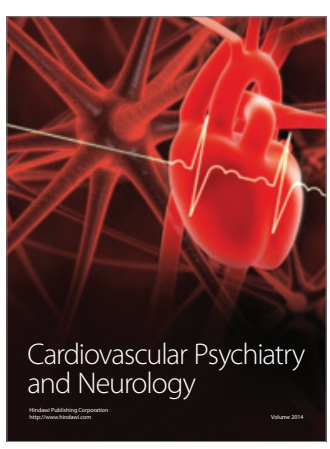

Parkinson's

Disease
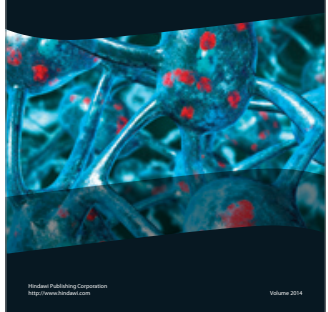